\title{
A CONCEPTUAL MODEL FOR INVESTIGATING BIM ADOPTION BY ORGANISATIONS
}

\author{
Ahmed L Ahmed ${ }^{1}$, John Kawalek ${ }^{2}$, and Mohamad Kassem ${ }^{3}$
}

\begin{abstract}
Studies investigating Building Information Modelling (BIM) adoption proliferated in recent years. Existing studies are characterised by both deficiencies in the adoption drivers and factors identified and an insufficient demarcation of key terms and concepts used. The suitability of using the results of these studies to investigate a conceptual model for BIM adoption is therefore impaired. This study presents (a) a holistic set of drivers and factors that influence BIM adoption by organisations, and (b) the theoretical fundamentals for the development of a conceptual model for BIM adoption by organisations. The set of drivers and factors for BIM adoption can be used by researchers and practitioners for different purposes (e.g., assessment, ranking, adoption strategies). The theoretical fundamentals of the proposed conceptual model combine the essential lenses from the pertinent theories (i.e., innovation diffusion theory, and institutional theory) and models (i.e., diffusion dynamic model: top-down diffusion dynamics including formal and informal mandates). The model can be used to empirically investigate the decisions to adopt BIM by organisations and understand the varying influence of different adoption drivers and factors.
\end{abstract}

Keywords: BIM, Systematic literature review, Conceptual model, Adoption drivers and factors.

\section{INTRODUCTION}

Building Information Modelling (BIM) is an expansive knowledge domain (Succar and Kassem 2016). Significant research has been conducted to investigate BIM drivers, and the BIM adoption and diffusion process. BIM adoption and diffusion studies often seek to develop approaches for forecasting BIM diffusion (Gledson 2015), and are generally focused on the diffusion phase, after BIM has been adopted (Kim, Park et al. 2015). Studies investigating BIM drivers and factors either use the key terms and concepts (e.g., implementation, readiness, adoption) interchangeably or provide insufficient details regarding the position of organisations considered within the adoption process. Adoption drivers and factors are also disjointedly available across several studies as a result of the specific theoretical lenses embraced by researchers (e.g., Cao, Li et al. 2014). This research aims to (a) identify an exhaustive list of drivers and factors that influence the decision to adopt BIM by organisations and (2) develop and combine the necessary theoretical fundamentals in a conceptual model that can for the empirical investigation of the BIM adoption process. The subsequent sections will respectively present: the

1 PhD Researcher, Sheffield School of Architecture, University of Sheffield, Sheffield, UK, alaahmed1@sheffield.ac.uk (Lecturer, Dept. of Architecture, University of Technology, Baghdad, Iraq)

2 Head of Operations Management \& Decision Sciences, Management School, University of Sheffield, Sheffield, UK, j.kawalek@sheffield.ac.uk

3 Associate Professor, Faculty of Engineering and Environment, Northumbria University, Newcastle, UK, mohamad.kassem@northumbria.ac.uk 
research method used; the set of BIM drivers and factors identified; and the conceptual model proposed.

\section{RESEARCH METHOD - SYSTEMATIC LITERATURE REVIEW}

This research employs a Systematic Literature Review (SLR) to minimise bias, address clear research questions, and perform an exploratory investigation to understand the reasons for heterogeneity (i.e., variations in outcomes) between apparently similar studies (Kamal and Irani 2014). Accumulating knowledge of several different but related research is considered an efficient approach to achieve a generalised and comprehensive overview on a particular issue (Abdul Hameed 2012). In addition, the SLR represents an explicit and reproducible method for collecting and combining existing research knowledge. Implementing the SLR helps to map out research extents of uncertainty to recognise gaps and suggest opportunities for future research. Kitchenham and Charters (2007) identifies planning, execution, and reporting results as the three main phases. Denyer and Tranfield (2009) provides well-defined stages of the SLR protocol: (1) formulation the review question, (2) locating studies, (3) study selection and evaluation, (4) analysis and synthesis, and finally (5) reporting the results.

\section{PERForming The SLR}

This research involved pre-defined and discrete activities, which can be grouped into three main phases: planning, executing, and reporting:

\subsection{Phase I- Planning the review}

This phase encompasses formulating the review/research questions and developing the SLR protocol to be executed in the Phase II. To fulfil the aim of this research, two research questions (RQ) were posed at this phase: (RQ1) what are the drivers impacting BIM adoption decision-making at organisation level within the construction industry; and (RQ2) what are the adopted theories, frameworks, and models for examining the innovation (i.e., BIM) adoption/diffusion process?

\subsection{Phase II- Executing the review}

In the phase the search strategy is designed to identify studies that are relevant to the two research questions. A range of search terms, obtained by decomposing each research question, were collated. A tentative title of 'BIM Adoption/Diffusion Drivers in the Construction Industry', alternative synonyms of search terms, and Boolean operators were used to guide the search of the databases resources. The considered online electronic included Scopus, Science Direct, Ethos, and Google Scholar. The studies returned were screened using inclusion and exclusion criteria) to ensure relevance to the research questions. A pilot search run was performed at this stage to further refine the selection criteria. A quality checklist (i.e., contribution, theoretical base, methodology, and analysis) was devised as part of a quality assessment (QA) process to ensure that the studies selected have adequate methodological rigour. The studies identified were then subjected to data extraction and data synthesis, respectively. In the data extraction stage, information extraction cards (i.e., structured tabular template) were used to systematically identify key attributes from the studies identified and ensure 
comparability. Finally, the findings and evidence in relation to each of the research question were collated and discussed at the data synthesis stage.

\subsection{Phase III- Reporting the review results}

\subsubsection{SLR execution result reporting}

Once the two search strings were executed, a total of 3110 papers were retrieved (i.e. 1084, 693, 1330, and 3 for Scopus, ScienceDirect, Google Scholar and Ethos, respectively) for the primary search in stage one. This initial set of papers was subjected to screening and checking throughout a multi-stage process (Figure 1): removal of duplicate papers; title and abstract checking to remove irrelevant papers; checking papers against inclusion and exclusion criteria, and quality assessment. At the end of this process, 34 papers progressed to the data extraction stage.

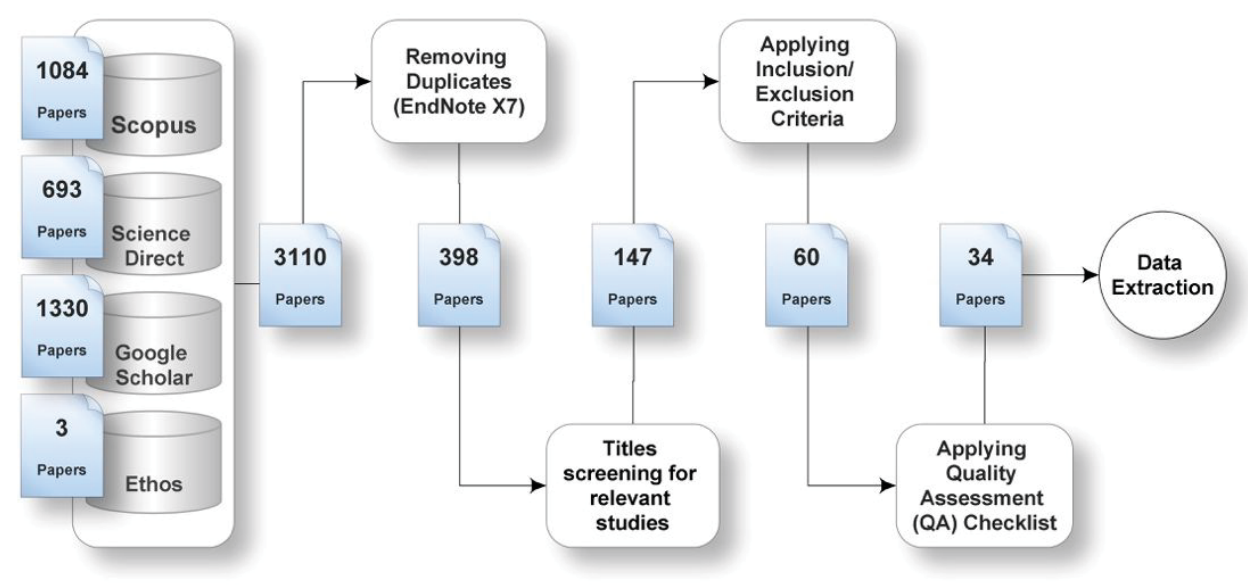

Figure 1: The SLR execution process

\subsubsection{Reporting the SLR data extraction results and discussion}

This section analyses and discusses the results of the systematic review. The first part provides a synthesis of the data and the second part discusses the outcomes in relation to the two research questions.

Each paper was given a unique tag (i.e., S1, S2, S3, etc.) with the letter 'S' prefix denoting 'Study'. Three optional answers were identified for each question: Y (Yes), $\mathrm{P}$ (Partly), or $\mathrm{N}(\mathrm{No})$. The score used for these answers is: $\mathrm{Y}=1, \mathrm{P}=0.5, \mathrm{~N}=0$ or not applicable. The results of the first part are summarised in table A (in the Appendix) for the 34 papers. $19(56 \%)$ papers address the field of BIM adoption whereas the remaining $15(44 \%)$ are focussed on the field of Information Technology (IT) or Information Systems (IS). Innovation adoption was discussed at three levels of organisational scales: Micro-level (i.e., organisational subdivisions, groups, and individuals) in $21(62 \%)$ papers, Macro-level (i.e., market subdivisions, sectors, industries and specialities) in 9 (26\%) studies, and Meso-level (i.e., project-centric organisational teams) in $4(12 \%)$. The overall score from the quality assessment (QA) of all papers is $87 \%$ and it is considered very high. $17(50 \%)$ papers scored $(100 \%)$.

All the 34 papers addressed RQ1 either fully by achieving full score 'Y' (i.e. S1, S10, S18, S27, S28, and S29) or partially 'P' (i.e., S2, S3, S4, S5, S6, S7, S8, S9, S11, S12, S13, S14, S15, S16, S17, S19, S20, S21, S22, S23, S25, S26, S30, S31, S32, S33, S34) resulting in an overall score of $75 \%$. As a result of addressing this question, a complete set of drivers 
and factors for BIM adoption is identified. In this context, drivers represent clusters of incentives and factors that contribute to greater propensity of adopting an innovation. Factors - within a driver cluster - represent key determinants that influence positively or negatively the decision process of innovation adoption.

The identified drivers can be grouped into three main categories:

- Innovation characteristics (i.e., innovation perceived attributes);

- Internal environment characteristics (i.e., adopter or organisation readiness); and

- External environment characteristics (isomorphic pressures).

The innovation characteristics, include factors such as relative advantages, compatibility, complexity, trialability, observability (Rogers 2003), perceived ease of use, and perceived usefulness (Ramanayaka and Venkatachalam 2015). The internal environment characteristics include factors such as organisational culture, firm size, top management support, client/owner willingness to change (Cao, Li et al. 2014). The external environment characteristics include coercive pressures, mimetic pressures, normative pressures (Fareed, Bazzoli et al. 2015), and competitive pressures (Oliveira, Thomas et al. 2014). Tables 1 presents an exhaustive list of the drivers and key factors influencing the decision to adopt BIM/ innovation.

$28(82 \%)$ papers were able to either address RQ2 by achieving full score ' $Y$ ' (i.e., S1, S3, S4, S6, S7, S10, S11, S13, S14, S16, S17, S18, S19, S20, S21, S24, S25, S26, S27, S28, S29, S30, S31, S32, S33, and S34), or partially 'P' (i.e., S9, and S12), whereas the 6 residual papers did not cover this aspect with zero score (i.e., 'N'). Therefore, these studies were able to provide $79 \%$ of the required information to answer this question. $26(76 \%)$ papers adopted theoretical standpoints to guide and analyse the process of BIM adoption. The key theories adopted included: Innovation Diffusion Theory (IDT) (53\%), Institutional Theory (INT) (26\%), Technology Acceptance Model (TAM) (21\%), mixed-theories (21\%), and Theory of Reasoned Action (TRA) (6\%).

Innovation Diffusion Theory (IDT) is the most widely used theory to explain the adopters' behaviours. IDT proposes five elements to describe the characteristics of an innovation: relative advantage, compatibility, complexity, trialability, and observability. It explains the characteristics of an adopter (i.e., internal characteristics of individuals or the decision-making unit) in terms of: socioeconomic characteristics, personality variables, and communication behaviour (Rogers 2003, p.282). IDT suggests a five-stage model of 'innovation-decision process': awareness, interest, decision, implementation, and confirmation (Rogers 2003, p.169). As IDT focuses on the behaviour of individuals in innovation adoption, numerous studies have combined IDT with other theories to investigate and explain the adoption process by organizations (Chwelos, Benbasat et al. 2001).

The Technology Acceptance Model (TAM) identifies two factors as determinants for the use of a new system: perceived ease of use (PEU) and perceived usefulness (Davis 1989). TAM establishes theoretical linkages among beliefs, intention, and action to explain system use. The user's belief (i.e. the PEU and PU) about a given system influences their behavioural intention to use, which in turn, determines the actual system use. TAM seeks to predict users' acceptance of a technological innovation and explains the behaviour of individuals against IT acceptance (Hameed, Counsell et al. 2012).

According to the Institutional Theory (INT), the external isomorphic pressures motivate organisations to perform behavioural and structural changes while seeking to acquire social legitimacy (DiMaggio and Powell 1983). The institutional pressures include: coercive, mimetic, and normative pressures (DiMaggio and Powell 1983, Fareed, 
Bazzoli et al. 2015). Organisations comply with formal pressures (mandates, regulations), mimic successful practices, or conform to informal restrictions (i.e., beliefs, norms, and conventions). The institutional legitimacy is determined as a result of the organisations response towards these pressures.

Table 1: Drivers and factors affecting BIM/innovation adoption

\begin{tabular}{|c|c|c|c|c|c|}
\hline \multicolumn{2}{|c|}{ BIM/Innovation characteristics } & \multicolumn{2}{|c|}{ External environment characteristics } & \multicolumn{2}{|c|}{ Internal environment characteristics } \\
\hline $\begin{array}{l}\text { Main adoption } \\
\text { factors }\end{array}$ & Studies & $\begin{array}{l}\text { Main adoption } \\
\text { factors }\end{array}$ & Studies & Main adoption factors & Studies \\
\hline Perceived Usefulness & S6, S9 & $\begin{array}{l}\text { Coercive pressures/ } \\
\text { forces }\end{array}$ & $\begin{array}{l}\text { S1, S3, S5, } \\
\text { S7, S8, S9, } \\
\text { S10, S12, } \\
\text { S13, S14, } \\
\text { S15, S17, } \\
\text { S18, S23, } \\
\text { S26, S27, } \\
\text { S28, S31, } \\
\text { S33 }\end{array}$ & Top management support & $\begin{array}{l}\text { S4, S9, } \\
\text { S16, S22, } \\
\text { S25, S26, } \\
\text { S27, S28, } \\
\text { S31, S34 }\end{array}$ \\
\hline Perceived Ease of Use & S6, S9 & Mimetic pressures & $\begin{array}{l}\text { S10, S12, } \\
\text { S22, S23, } \\
\text { S26, S27 }\end{array}$ & Communication behaviour & $\begin{array}{l}\text { S9, S25, } \\
\text { S29 }\end{array}$ \\
\hline Relative advantage & $\begin{array}{l}\text { S6, S9, S28, } \\
\text { S31 }\end{array}$ & Normative pressures & $\begin{array}{l}\text { S4, S7, S8, } \\
\text { S9, S10, } \\
\text { S23, S26, } \\
\text { S27 }\end{array}$ & $\begin{array}{l}\text { Financial resources } \\
\text { (Perceived cost) }\end{array}$ & $\begin{array}{l}\text { S3, S5, S7, } \\
\text { S9, S17, } \\
\text { S18, S20, } \\
\text { S26, S27, } \\
\text { S33, S34 }\end{array}$ \\
\hline Compatibility & S6, S11, S18 & $\begin{array}{l}\text { Market forces and } \\
\text { Supply chain integration }\end{array}$ & $\begin{array}{l}\text { S4, S5, S7, } \\
\text { S8, S9, S17, } \\
\text { S18, S26, } \\
\text { S27, S31, } \\
\text { S34 }\end{array}$ & Organizational readiness & $\begin{array}{l}\text { S3, S4, S7, } \\
\text { S9, S18, } \\
\text { S25, S26, } \\
\text { S27, S28, } \\
\text { S29, S31, } \\
\text { S34 }\end{array}$ \\
\hline Complexity & S6, S31 & & & Social motivations & $\begin{array}{l}\text { S9, S11, } \\
\text { S18, S22, } \\
\text { S24, S25, } \\
\text { S26, S31, } \\
\text { S33 }\end{array}$ \\
\hline Trialability & S6 & & & Organisational culture & $\begin{array}{l}\text { S8, S9, } \\
\text { S20, S24, } \\
\text { S26, S32 }\end{array}$ \\
\hline Observability & S9 & & & Willingness/intention & $\begin{array}{l}\text { S3, S4, S5, } \\
\text { S7, S9, } \\
\text { S13, S24, } \\
\text { S25, }\end{array}$ \\
\hline Technological factors & $\begin{array}{l}\text { S4, S8, S9, } \\
\text { S17, S18, S24 }\end{array}$ & & & Organisation size & $\mathrm{S} 26, \mathrm{~S} 28$ \\
\hline
\end{tabular}

There is a limited concurrent use of IDT and INT to examine the factors influencing organisational behaviour to innovation adoption. Only 5 papers (i.e., S12, S27, S29, S33, and S34) included aspects from the two theories: Paper S12 used the two theories to clarify the conceptual constructs; papers S27 and S29 have mainly used the INT with a subtle reference to the IDT; Papers S33 and S34 have focused on a few selected aspects of IDT (i.e., control variables and economic motivations for S33, and BIM technology, top management support for S34) and INT (i.e., social motivations for S34, and client support and trading partner for S34). The proposed conceptual model, proposed later in the paper, will fully combine the two theories to investigate the decision to adopt BIM by organisations.

\section{CONCEPTUAL MODEL FOR INVESTIGATING BIM ADOPTION BY ORGANISATIONS}

The analysis and synthesis of the SRL findings are used to develop a conceptual model for the empirical investigation of BIM adoption decisions by organisations. In particular, the conceptual model blends the theories, drivers and factors identified and synthesised 
in the SLR (Figure 2). The conceptual model merges together an adapted view of the innovation adoption process by Rogers (2003) and key theoretical elements of the Innovation Diffusion Theory (IDT) and Institutional Theory (INT) theories. The driver clusters include: innovation characteristics, internal environment characteristics, and external environment characteristics.

The innovation characteristics- mentioned in Table 1- will help to investigate the influence of the BIM characteristics on adoption decisions. In this context, BIM is considered as: a disruptive innovation (Eastman, Teicholz et al. 2011) that involves both a procedural change and a technological shift (Succar 2009, Eastman, Teicholz et al. 2011), a "boundless" (Harty 2005, P.51) or a "systemic" innovation (Taylor and Levitt 2004, P.84). The internal environment characteristics and the external environment characteristics are investigated using both the IDT and the INT as two complementary theories. The IDT will provide the theoretical requisites for investigating the BIM characteristics (i.e. innovation attributes) and the organisation internal environment characteristics (i.e., adopter or organisation readiness). The INT will help to investigate the external environment characteristics (i.e. institutional isomorphic pressures).

The interactions of the considered elements from the IDT and INT on the adoption process are shown in the proposed five-stage model which is an adaptation of Roger s's innovation decision process (2003). The adapted process includes five stages: Awareness, interest to adopt (i.e., intention), point of adoption (PoA) stage, implementation, and confirmation.

The awareness stage (Stage one) occurs when an organisation or a decision-making unit is exposed to a new innovation (i.e. BIM) and starts to gain knowledge about it. This stage might be triggered either by some of the internal environment characteristics (e.g., communication behaviour, social motivations, organisational culture, and innovation willingness) and/or the external environment characteristics (e.g., coercive pressures, mimetic pressures, normative pressures, and market forces).

The intention/interest to adopt stage (Stage two) unfolds when an organisation or a decision-making unit develops a favourable or an unfavourable attitude towards the innovation. It is mainly affected by the perceived characteristics of the innovation (i.e., perceived usefulness, perceived ease of use, relative advantage, compatibility, complexity, trialability, observability, and technological factors).

The Point of Adoption stage (Stage three) is adopted from a concept presented by Succar and Kassem (2015), (2016)and is used to adapt the five-stage model of Rogers (2003). This adaptation is necessary to take into account the peculiarities of BIM as both: a disruptive innovation including technological and procedural shift, and a staged innovation including the three stages of modelling, collaboration, and integration (Succar 2009). It starts after the organisation (or organisation unit) has developed a favourable attitude towards the BIM innovation - or one of its specific stages - and it signals the start of a wilful set of experimental activities to implement the BIM innovation. At the end of this stage, the organisation might accept or reject the innovation.

The implementation stage (Stage four) occurs when an organisation or a decisionmaking unit starts using the innovation - or one of its specific stages - in real world projects following the successful experimental implementation activities at Stage three.

Finally, the confirmation stage (Stage five) is reached when an organisation or a decision-making unit requests support to further diffuse the adopted BIM innovation or one of its specific stages - across its adopter population.

The proposed conceptual model (Figure 2) will be further adapted - as part of future research - to recognise the non-linear and non-sequential nature of the BIM adoption 
process: The adoption stages (i.e. Stage 1 to Stage 5) can unfold in cycles within an organisation or a decision-making unit for each stage (i.e. modelling, collaboration, and integration) of the BIM innovation.

In the second part of this research, the model will be used to conduct a retrospective analysis - i.e., by considering a sample of organisation that have already crossed the point of adoption stage - within a specific market (e.g., the United Kingdom).

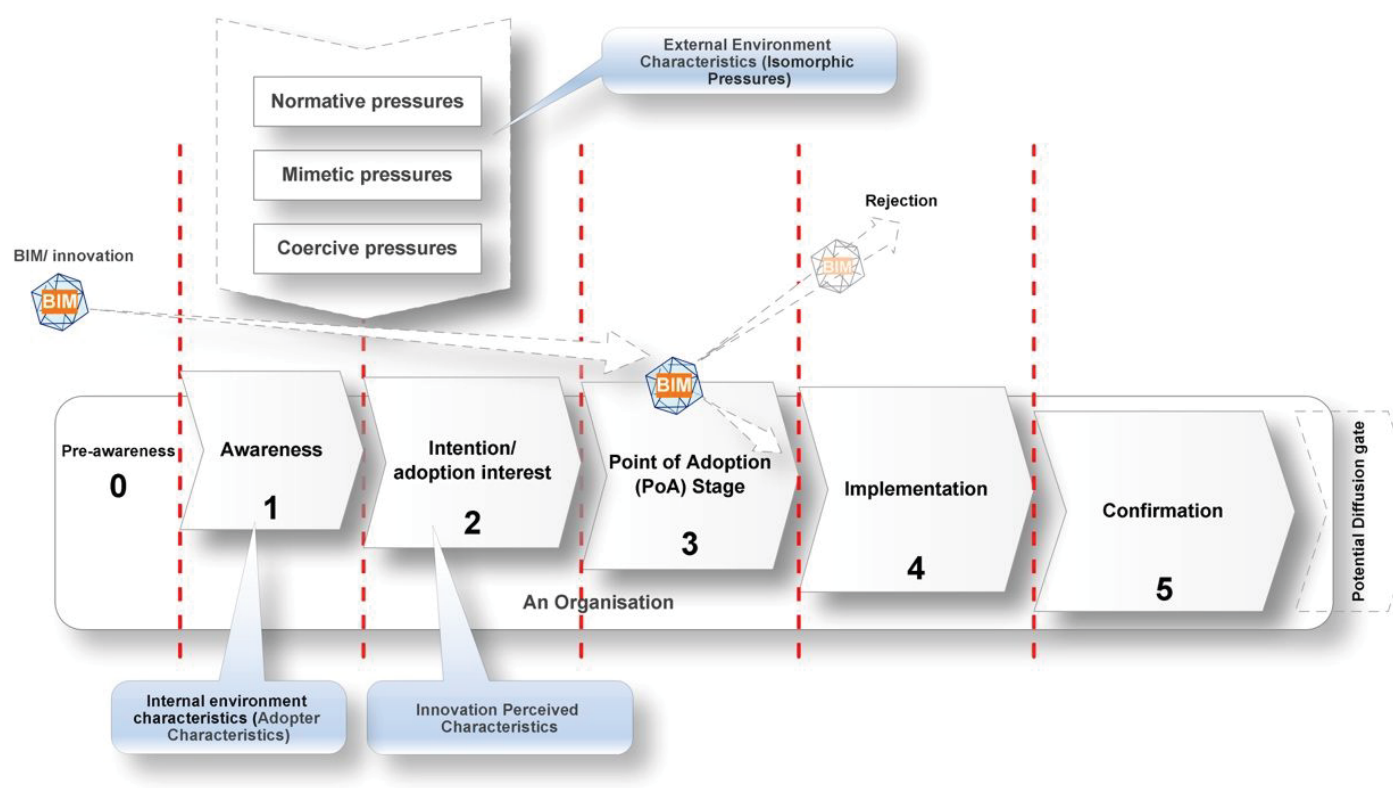

Figure 2: Conceptual Model for investigating BIM adoption decisions, adapted from Rogers's (2003) theory

\section{CONCLUSIONS}

This paper presented a systematic literature review and proposed a conceptual model for the adoption process of BIM innovation. A comprehensive set of drivers and factors that influence the decisions of organisations to adopt BIM was collated from the systematic literature review. The proposed conceptual model combines elements from the IDT and the INT and considers their interactions with the five stages of the adoption process of BIM innovation. The set of drivers and factors and the proposed conceptual model can be used by researchers to conduct empirical investigations of the adoption process of BIM innovation. Combined with empirical evidence, the result can be used to plan BIM adoption/diffusion actions within markets (e.g., effectiveness of formal mandate against informal mandate on BIM diffusion).

\section{ACKNOWLEDGMENTS}

This work has been sponsored by the Iraqi Ministry of Higher Education and Scientific Research (MOHESR) jointly with the University of Technology, Baghdad, Iraq.

\section{REFERENCES}

Abdul Hameed, M. (2012). Adoption process of information technology (IT) innovations in organizations. Doctoral (PhD thesis), Brunel University. 
Cao, D., H. Li and G. Wang (2014). "Impacts of isomorphic pressures on BIM adoption in construction projects." Journal of Construction Engineering and Management, 140(12).

Chwelos, P., I. Benbasat and A. S. Dexter (2001). "Research report: Empirical test of an EDI adoption model." Information systems research, 12(3): 304-321.

Davis, F. D. (1989). "Perceived Usefulness, Perceived Ease of Use, and User Acceptance of Information Technology." MIS Quarterly, 13(3): 319-340.

Denyer, D. and D. Tranfield (2009). Producing a systematic review. The SAGE handbook of organizational research methods, D. A. Buchanan and A. Bryman. London, Sage Publications Ltd: pp. 671-689.

DiMaggio, P. J. and W. W. Powell (1983). The Iron Cage Revisited: Institutional Isomorphism and Collective Rationality in Organizational Fields. American Sociological Review 48(2): 147-160.

Eastman, C., P. Teicholz, R. Sacks and K. Liston (2011). BIM handbook : A Guide to Building Information Modeling for Owners, Managers, Designers, Engineers and Contractors. Hoboken, New Jersey, by John Wiley \& Sons, Inc.

Fareed, N., G. J. Bazzoli, S. S. Farnsworth Mick and D. W. Harless (2015). The influence of institutional pressures on hospital electronic health record presence. Social Science \& Medicine 133: 28-35.

Gledson, B. (2015). Investigating the diffusion of 4D BIM Innovation.

Hameed, M. A., S. Counsell and S. Swift (2012). A conceptual model for the process of IT innovation adoption in organizations. Journal of Engineering and Technology Management, 29(3): 358-390.

Harty, C. (2005). Innovation in construction: a sociology of technology approach" Building Research \& Information, 33(6): 512-522.

Kamal, M. M. and Z. Irani (2014). Analysing supply chain integration through a systematic literature review: a normative perspective. Supply Chain Management: An International Journal 19(5/6): 523-557.

Kim, S., C. H. Park and S. Chin (2015). Assessment of BIM acceptance degree of Korean AEC participants. KSCE Journal of Civil Engineering.

Kitchenham, B. and S. Charters (2007). Guidelines for performing systematic literature reviews in software engineering. Technical report, Ver. 2.3 EBSE Technical Report. EBSE.

Oliveira, T., M. Thomas and M. Espadanal (2014). Assessing the determinants of cloud computing adoption: An analysis of the manufacturing and services sectors. Information \& Management, 51(5): 497-510.

Ramanayaka, C. D. D. and S. Venkatachalam (2015). Reflection on BIM Development Practices at the Pre-maturity. Procedia Engineering, 123: 462-470.

Rogers, E. M. (2003). Diffusion of Innovations, 5th Edition, Free Press.

Succar, B. (2009). Building information modelling framework: A research and delivery foundation for industry stakeholders. Automation in Construction, 18(3): 357-375.

Succar, B. and M. Kassem (2015). Macro-BIM adoption: Conceptual structures. Automation in Construction, 57: 64-79.

Succar, B. and M. Kassem (2016). Building Information Modelling: Point of Adoption. CIB World Congress. Tampere Finland.

Taylor, J. E. and R. E. Levitt (2004). A new model for systemic innovation diffusion in project-based industries. Project Management Institute International Research Conference. 


\section{APPENDIX:}

Table A: The Total 34 Included Papers in the SLR

\begin{tabular}{|c|c|c|}
\hline ID & Author & Title \\
\hline S1 & $\begin{array}{l}\text { (Aranda-Mena and Wakefield, } \\
\text { 2006) }\end{array}$ & Interoperability of building information - Myth of reality? \\
\hline S2 & (Cao et al., 2015) & Practices and effectiveness of building in formation modelling in construction projects in China \\
\hline S3 & (Gu and London, 2010) & Understanding and facilitating BIM adoption in the AEC industry \\
\hline S4 & (Xu et al., 2014) & Users-orientated evaluation of building information model in the Chinese construction industry \\
\hline S5 & (Rogers et al., 2015) & $\begin{array}{l}\text { Adoption of Building In formation Modelling technology (BIM): Perspectives from Malaysian } \\
\text { engineering consulting services firms }\end{array}$ \\
\hline S6 & (Kim et al., 2015) & Assessment of BIM acceptance degree of Korean AEC participants \\
\hline S7 & (Takim et al., 2013) & $\begin{array}{l}\text { Building Information Modeling (BIM): A New Paradigm for Quality of Life Within Architectural, } \\
\text { Engineering and Construction (AEC) Industry }\end{array}$ \\
\hline S8 & (Abubakar et al., 2014) & $\begin{array}{l}\text { Contractors perception of the factors affecting building information modelling (BIM) adoption in the } \\
\text { Nigerian construction industry }\end{array}$ \\
\hline S9 & (Mom et al., 2014) & $\begin{array}{l}\text { Developing critical success factors for the assessment of BIM technology adoption: Part II. Analysis and } \\
\text { results }\end{array}$ \\
\hline S10 & (Cao et al., 2014) & Impacts of isomorphic pressures on BIM adoption in construction projects \\
\hline S11 & (London and Singh, 2013) & Integrated construction supply chain design and delivery solutions \\
\hline $\mathrm{S} 12$ & (Succar and Kassem, 2015) & Macro-BIM adoption: Conceptual structures \\
\hline S13 & (Singh and Holmstrom, 2015) & Needs and technology adoption: Observation from BIM experience \\
\hline S14 & $\begin{array}{l}\text { (Ramanayaka and } \\
\text { Venkatachalam, 2015) }\end{array}$ & Reflection on BIM Development Practices at the Pre-maturity \\
\hline S15 & (Juszczyk et al., 2015) & Prospects for the use of BIM in Poland and the Czech Republic - Preliminary Research Results \\
\hline S16 & (Son et al., 2015) & $\begin{array}{l}\text { What drives the adoption of building information modeling in design organizations? An empirical } \\
\text { investigation of the antecedents affecting architects' behavioral intentions }\end{array}$ \\
\hline S17 & (Seed, 2015) & $\begin{array}{l}\text { The Dynamics of BIM Adoption: A Mixed Methods Study of BIM as an Innovation within the United } \\
\text { Kingdom Construction Industry }\end{array}$ \\
\hline S18 & (Waarts et al., 2002) & The dynamics of factors affecting the adoption of innovations \\
\hline S19 & (Sherer et al., 2016) & Applying institutional theory to the adoption of electronic health records in the U.S \\
\hline S20 & (Wu and Chen, 2014) & $\begin{array}{l}\text { A stage-based diffusion of IT innovation and the BSC performance impact: A moderator of technology- } \\
\text { organization-environment }\end{array}$ \\
\hline S21 & $\begin{array}{l}\text { (Damanpour and } \\
\text { Gopalakrishnan, 2001) }\end{array}$ & The Dynamics of the Adoption of Product and Process Innovations in Organizations \\
\hline S22 & (Shim et al., 2009) & Empirical analysis of risk-taking behavior in IT platform migration decisions \\
\hline S23 & (Yitmen, 2007) & The challenge of change for innovation in construction: A North Cyprus perspective \\
\hline S24 & (Peansupap and Walker, 2005) & $\begin{array}{l}\text { Exploratory factors influencing information and communication technology diffusion and adoption } \\
\text { within Australian construction organizations: a micro analysis }\end{array}$ \\
\hline S25 & (Talukder, 2012) & Factors affecting the adoption of technological innovation by individual employees: An Australian study \\
\hline S26 & (Hameed et al., 2012) & A conceptual model for the process of IT innovation adoption in organizations \\
\hline S27 & (Tsai et al., 2013) & A study of the institutional forces influencing the adoption intention of RFID by suppliers \\
\hline S28 & (Oliveira et al., 2014) & $\begin{array}{l}\text { Assessing the determinants of cloud computing adoption: An analysis of the manufacturing and services } \\
\text { sectors }\end{array}$ \\
\hline S29 & (Henderson et al., 2012) & $\begin{array}{l}\text { The determinants of inter-organizational and internal in-house adoption of XBRL: A structural equation } \\
\text { model }\end{array}$ \\
\hline S30 & (Fareed et al., 2015) & The influence of institutional pressures on hospital electronic health record presence \\
\hline S31 & (Tsai et al., 2010) & Determinants of RFID adoption intention: Evidence from Taiwanese retail chains \\
\hline S32 & (Liu et al., 2010) & $\begin{array}{l}\text { The role of institutional pressures and organizational culture in the firm's intention to adopt internet- } \\
\text { enabled supply chain management systems. }\end{array}$ \\
\hline S33 & (Cao et al., 2016) & $\begin{array}{l}\text { Linking the Motivations and Practices of Design Organizations to Implement Building Information } \\
\text { Modeling in Construction Projects: Empirical Study in China }\end{array}$ \\
\hline S34 & (Ahuja et al., 2016) & Adoption of BIM by architectural firms in India: technology - organization- environment perspective \\
\hline
\end{tabular}

